\title{
An investigation into the validity of cervical spine motion palpation using subjects with congenital block vertebrae as a 'gold standard' Barry K Humphreys*1, Marianne Delahaye ${ }^{2}$ and Cynthia K Peterson ${ }^{1}$
}

\author{
Address: ${ }^{1}$ Graduate Education and Research, Canadian Memorial Chiropractic College, 1900 Bayview Avenue, Toronto, Ontario, Canada and \\ ${ }^{2}$ Research Department, Anglo-European College of Chiropractic (AECC), 13-15 Parkwood Road, Bournemouth, England \\ Email: Barry K Humphreys* - khumphreys@cmcc.ca; Marianne Delahaye - mcook@aecc.ac.uk; Cynthia K Peterson - cpeterson@cmcc.ca \\ * Corresponding author
}

Published: 15 June 2004

BMC Musculoskeletal Disorders 2004, 5:19
Received: 21 April 2004

Accepted: 15 June 2004

This article is available from: http://www.biomedcentral.com/I47/-2474/5/19

(c) 2004 Humphreys et al; licensee BioMed Central Ltd. This is an Open Access article: verbatim copying and redistribution of this article are permitted in all media for any purpose, provided this notice is preserved along with the article's original URL.

\begin{abstract}
Background: Although the effectiveness of manipulative therapy for treating back and neck pain has been demonstrated, the validity of many of the procedures used to detect joint dysfunction has not been confirmed. Practitioners of manual medicine frequently employ motion palpation as a diagnostic tool, despite conflicting evidence regarding its utility and reliability. The introduction of various spinal models with artificially introduced 'fixations' as an attempt to introduce a 'gold standard' has met with frustration and frequent mechanical failure. Because direct comparison against a 'gold standard' allows the validity, specificity and sensitivity of a test to be calculated, the identification of a realistic 'gold standard' against which motion palpation can be evaluated is essential. The objective of this study was to introduce a new, realistic, 'gold standard', the congenital block vertebra (CBV) to assess the validity of motion palpation in detecting a true fixation.

Methods: Twenty fourth year chiropractic students examined the cervical spines of three subjects with single level congenital block vertebrae, using two commonly employed motion palpation tests. The examiners, who were blinded to the presence of congenital block vertebrae, were asked to identify the most hypomobile segment(s). The congenital block segments included two subjects with fusion at the $\mathrm{C2}$ 3 level and one with fusion at C5-6. Exclusion criteria included subjects who were frankly symptomatic, had moderate or severe degenerative changes in their cervical spines, or displayed signs of cervical instability. Spinal levels were marked on the subject's skin overlying the facet joints from $\mathrm{Cl}$ to $\mathrm{C7}$ bilaterally and the motion segments were then marked alphabetically with ' $\mathrm{A}$ ' corresponding to $\mathrm{CI}-2$.

Kappa coefficients $(K)$ were calculated to determine the validity of motion palpation to detect the congenitally fused segments as the 'most hypomobile' segments. Sensitivity and specificity of the diagnostic procedure were also calculated.

Results: Kappa coefficients $(K)$ showed substantial overall agreement for identification of the segment of greatest hypomobility $(K=0.65)$, with substantial $(K=0.76)$ and moderate $(K=0.46)$ agreement for hypomobility at C2-3 and C5-6 respectively. Sensitivity ranged from 55\% at the C5-6 CBV to 78\% at the C2-3 level. Specificity of the procedure was high (91 -98\%).

Conclusion: This study indicates that relatively inexperienced examiners are capable of correctly identifying inter-segmental fixations (CBV) in the cervical spine using 2 commonly employed motion palpation tests. The use of a 'gold standard' (CBV) in this study and the substantial agreement achieved lends support to the validity of motion palpation in detecting major spinal fixations in the cervical spine.
\end{abstract}




\section{Background}

Practitioners who treat patients with musculoskeletal disorders generally employ a number of manually applied examination techniques $[1,2]$. For the cervical spine, these techniques commonly consist of passive range-of-motion tests [3-6], pressure over the zygapophyseal joints $[7,8]$, palpation tenderness $[9,10]$, spinal stiffness $[11,12]$, and passive intervertebral motion or motion palpation $[13,14]$. Active cervical range-of-motion is now commonly measured using mechanical devices $[5,6]$.

In general, manual examination tests are used to detect and assess mechanical dysfunction of the cervical spine $[15,16]$. Test results are also used as clinical indicators for the application of manual therapy $[16,17]$. It is theorized that patients with mechanical neck pain may exhibit any or all of the findings consisting of increased spinal stiffness, localized muscle and joint pain, and reduced global as well as intersegmental range-of-motion at the site(s) of dysfunction. Consequently, active range-of-motion is used to evaluate global restrictions in cervical spine movement; provocative palpation tests of connective tissues and zygapophyseal joints to elicit pain from inflamed or damaged tissues; spinal stiffness tests to measure segmental motion; and intervertebral motion palpation to assess intersegmental dysfunction in terms of quantity and quality of intersegmental movement [16].

For any test to be useful in the clinical setting, it needs to be valid and reliable [18]. Unfortunately many manual examination tests for the cervical spine have demonstrated only poor to moderate reliability $[1-3,5,10,13,14]$. However, some recent studies suggest that palpation of cervical spine tenderness, reduced range of motion and some forms of motion palpation may be more reliable than previously reported $[2,4,7,13]$. There is now some evidence to suggest that physical impairments, functional limitations and disability are related in patients with cervical spine dysfunction $[4,29]$.

Dysfunction of the cervical spine is commonly evaluated, at least in part, using motion palpation techniques. In particular, intersegmental motion palpation has been studied extensively, but this has been mostly for the lumbar spine [19-24]. During the $1980 \mathrm{~s}$ and early $1990 \mathrm{~s}$, a number of intra- and interexaminer reliability studies of cervical spine intersegmental motion palpation were also conducted $[25,26]$. Results ranged from good to poor, or to no difference compared to that expected by chance alone $[25,26,30]$. Critics suggested variations of results were mainly due to varying quality of study design and statistical analysis [28-30]. Another major criticism of reliability studies in general was the lack of an appropriate 'gold standard' with which to compare the presence or absence of mechanical dysfunction $[31,32]$. A recent review of spi- nal palpatory diagnostic procedures identified only 3 studies related to the validity of motion palpation [33]. All of these studies involved the lumbar spine, used mechanical models and did not incorporate the specific influence that ligament and muscle attachments would have on intersegmental motion. Many of these models were subject to mechanical failure during data collection $[31,34]$. Only zygapophyseal joint injections have been used as an in vivo 'gold standard' for assessing cervical spine pain $[35,36]$. Currently no study utilizing a 'gold standard' has been performed in vivo to evaluate the validity of cervical spine intersegmental motion palpation.

This study proposes a new 'gold standard' of fixation, congenitally blocked (fused) vertebrae (CBV), which is without the limitations of previous studies. When two adjacent vertebrae are osseously fused from birth, this joined unit is known as congenital block vertebrae. Embryologically, congenital block vertebrae are the result of failure of the normal segmentation process of the somites during the period of differentiation, at 3-8 foetal weeks. There is no motion at the level of congenital block vertebrae, as noted in flexion and extension radiographic analysis, resulting in excessive mobility and early degenerative changes at the adjacent unfused motion segments [37]. Single congenital fusions are common anomalies, found most often at the C2-3 and C5-6 levels [37] (Figure $1)$.

The purpose of this study is to investigate the validity of motion palpation of the cervical spine in subjects with congenital block vertebrae.

\section{Methods \\ Participants / Subjects}

Three subjects previously attending the Anglo-European College of Chiropractic (AECC) clinic, who had been diagnosed with a single level congenital fusion in the cervical spine, were included in this study. Two of these individuals had fusion at the C2-3 level and one was fused at C5-6. None of these subjects were frankly symptomatic at the time of data collection, had moderate or severe degenerative changes in their cervical spines, or displayed signs of cervical instability. Prior to their participation, the study risks, benefits and examination procedures were described to them. All subjects gave written consent to participate.

\section{Examiners}

Twenty $4^{\text {th }}$ year students at the AECC agreed to examine the cervical spines of the three subjects. Each examiner was instructed to perform motion palpation as taught in the undergraduate programme and to report the 'most fixed' motion segment. All examiners had received three 


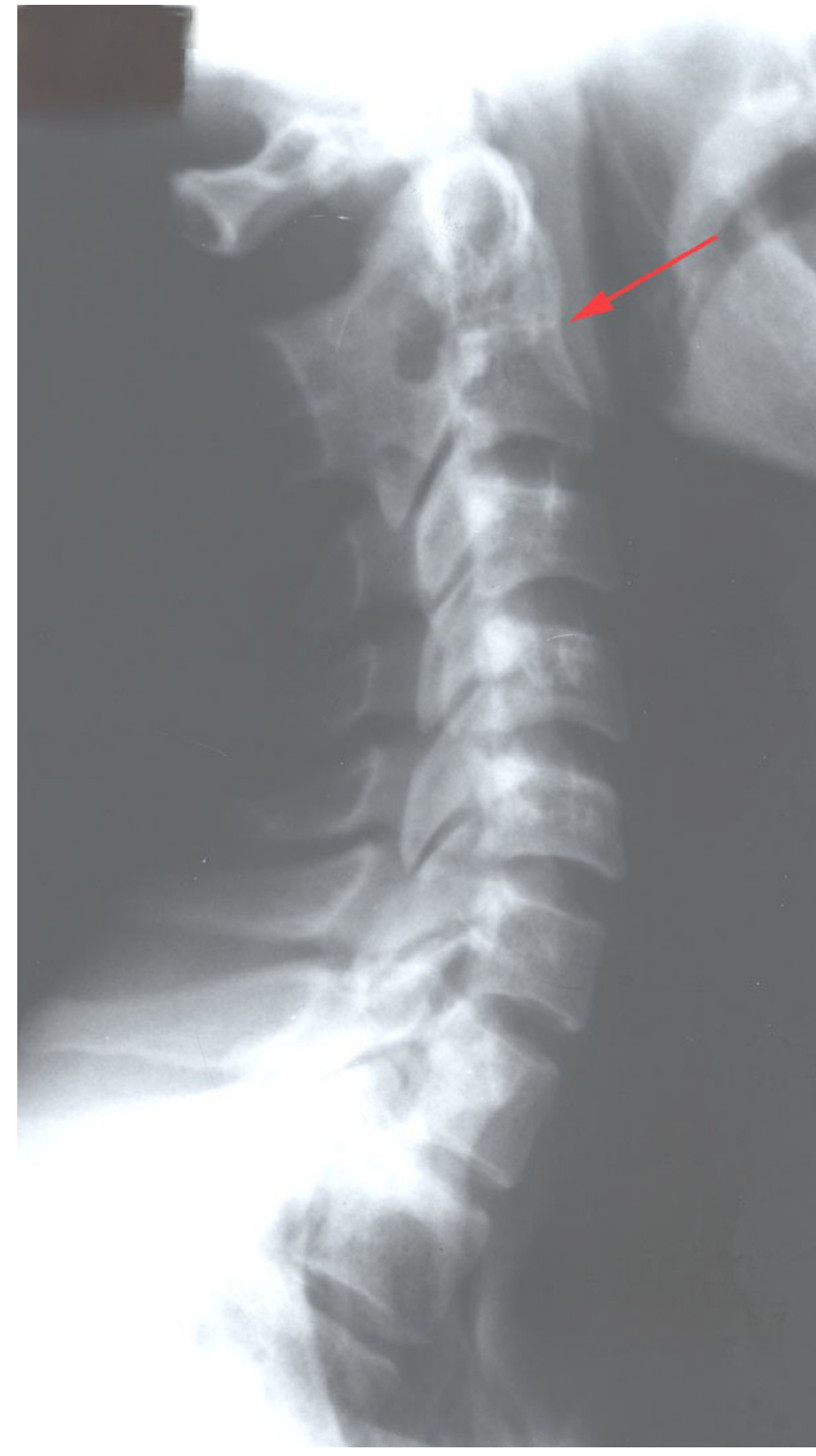

Figure I

Congenital fusion of $\mathrm{C} 2-3$

years of motion palpation training as well as a review of the procedure and revision handouts prior to participation. Examiners were given no information about the subjects and were thus unaware that each had congenital block vertebra.

\section{Procedures}

With the patient seated and their head in a neutral position, marks were drawn on the skin overlying the facet joints of $\mathrm{C} 1$ to $\mathrm{C} 7$ bilaterally. This was done by using the occiput, and the $\mathrm{C} 2$ and $\mathrm{C} 7$ spinous processes as land-

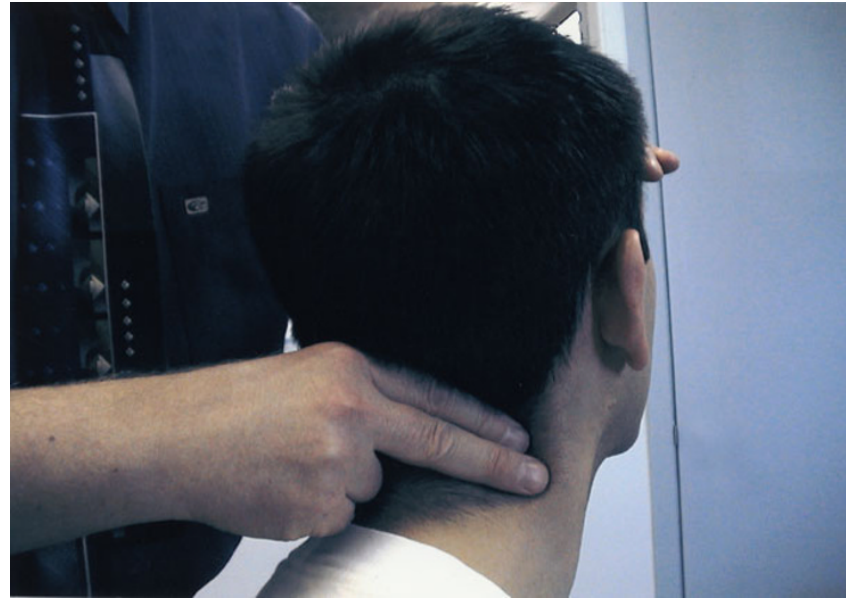

\section{Figure 2}

Palpation procedure for intersegmental motion in rotation

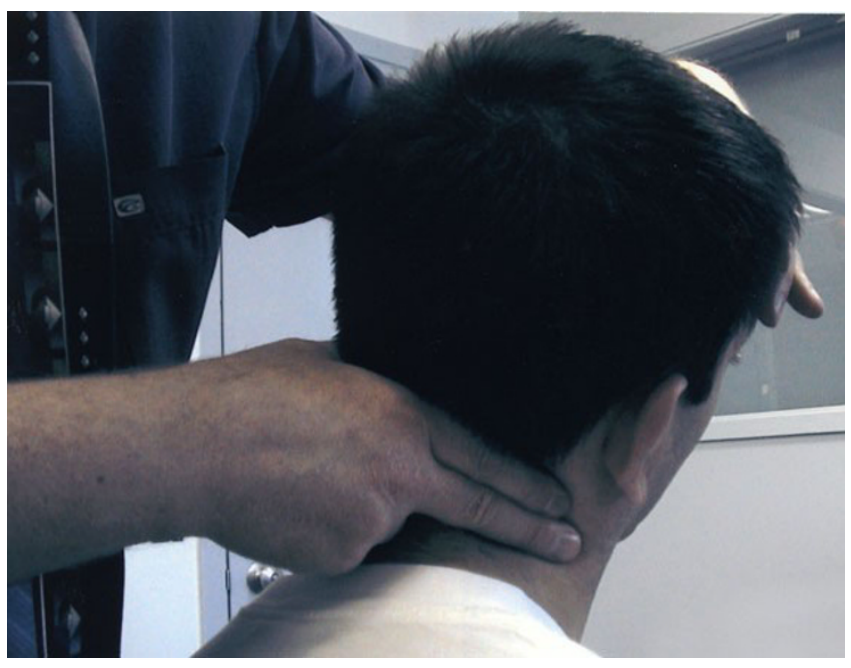

\section{Figure 3}

Palpation procedure for intersegmental motion in lateral flexion

marks. The intervertebral motion units were then marked alphabetically on the patient, "A" corresponding to C1-2, "B" to C2-3, etc. Patients were requested not to engage in verbal/visual communication with the examiners.

Each examiner independently evaluated the subjects for fixations, by palpating their cervical spines from $\mathrm{C} 1$ to $\mathrm{C} 7$ while the subject was in a seated position. Palpation was done first in rotation (Figure 2 ) and then in lateral flexion (Figure 3). The exact level of the most severe fixation find- 
Table I: Validity Results

\begin{tabular}{llll}
\hline & All Blocks & C2-3 Block & C5-6 Block \\
\hline Kappa Values & $\mathrm{K}=0.675$ & $\mathrm{~K}=0.756$ & $\mathrm{~K}=0.460$ \\
& $\mathrm{SE}=0.04 \mathrm{SE}=0.045$ & $\mathrm{~S}=0.091$ \\
Specificity & $\mathrm{Z}=17.067$ & $\mathrm{Z}=16.823$ & $91 \%$ \\
Sensitivity & $98 \%$ & $98 \%$ & $55 \%$ \\
\hline
\end{tabular}

$K=$ Kappa coefficient $S E=$ Standard Error $Z=$ Test Statistic Specificity is the ability to correctly identify non-fixed segments Sensitivity is the ability to detect a fixation if present

ing was demonstrated to one of the authors. If more than one fixation was identified, the examiners were asked to determine which of the fixations they considered to be the 'most hypomobile', and this information was recorded. Examiners were instructed not to discuss their palpatory findings with each other.

\section{Outcome Measures}

The validity of the motion palpation procedures was assessed comparing the examiners' identified 'most hypomobile' level to the 'gold standard' level of the congenital block vertebra. The calculation of Kappa coefficients was performed to determine whether actual inter-examiner agreements reflected concordance beyond chance. A Kappa value $<0.00=$ poor agreement, $0.01-0.20=$ slight agreement, $0.21-0.40=$ fair agreement, $0.41-0.60=$ moderate agreement, $0.61-0.80=$ substantial agreement, and $0.81-1.00=$ almost perfect agreement (26). Kappa coefficients were also calculated for the two different levels of CBV, in order to distinguish whether the data could demonstrate any difference in validity of motion palpation in detecting a 'fixation' at different spinal levels (C2-3 compared to C5-6).

The specificity and sensitivity of these motion palpation procedures was also determined. Sensitivity in this study was defined as the ability to detect a fixation if it is present, and specificity was defined as the ability to correctly identify non-fixed segments.

\section{Results}

The sensitivity, specificity and Kappa coefficients were calculated from the individual examiner's 'most hypomobile' finding compared to the CBV gold standard (Table 1). These results indicate a high rate of correct 'fixation' identification. The Kappa values for all patients $(\mathrm{K}=$ 0.675 ) indicated substantial agreement beyond chance. The results from the two subjects with C2-3 congenital fusion was even higher, $\mathrm{K}=0.756$, whilst agreement for palpation of the subject with the congenital fusion at the C5-6 level was moderate $(\mathrm{K}=0.460)$. The specificity was also high (91\% for C5-6 and 98\% at C2-3), indicating that examiners could identify non-fixed segments most of the time. The sensitivity was $74 \%$ overall $(55 \%$ for the C5-6 block, and $78 \%$ at C2-3). It was interesting to note that in patient number 2, many examiners identified an upper cervical segment as the most hypomobile, despite the CBV existing at the C5-6 level.

\section{Discussion}

This study was unique in employing an in-vivo gold standard of fixation in the form of congenital block vertebrae. It allowed the validity of motion palpation in the detection of segmental hypomobility to be evaluated, whilst omitting some of the experimental design limitations, which confined and confounded the previous studies.

Although previous studies have cast significant doubt on the reliability and validity of motion palpation for the diagnosis of a manipulable lesion [21-26,28], clinicians still continued to use this procedure in their practices. Their clinical judgment appeared to take precedence over the research findings. Perhaps these clinicians, functioning in the reality of the practice situation, sensed the limitations of the research settings and still felt that they were able to detect the individual fixation/s. The results of this study suggest that even student examiners, with less experience than practicing clinicians, were able to detect the presence or absence of 'fixation' in the cervical spine using specific motion palpation techniques in lateral flexion and rotation. The overall Kappa value of $\mathrm{K}=0.675$ represents substantial agreement beyond chance. These positive findings support the clinical use of motion palpation, and are arguably the most significant to date, since previous investigations have provided little evidence of the accuracy, validity or reliability of this procedure [28].

The degree of agreement reflected in these results may be accounted for by the use of an in-vivo gold standard, which closely approximates a true fixation. Not only is no motion allowed at the level of the CBV, but as previously described, the anomaly can result in increased motion and potential instability at adjacent motion segments 
[37]. The relative 'fixation' feel at the CBV would therefore be enhanced, and its detection further facilitated. The high Kappa values obtained in this study may also have been assisted by the marking of the IVMUs on the subjects.

The results, while not flawless, are encouraging in considering that even the most fundamental orthopaedic procedures have been shown to have less than perfect specificity and sensitivity [38]. An attempt was made in this study to limit variation in palpatory technique used by the examiners, in order to increase the tests reproducibility. The use of examiners with the same training and experience, as well as specific instruction as to the techniques to be used, served to standardize the motion palpation procedures performed, and may be one factor which contributed to the relatively high specificity and sensitivity scores.

Kappa coefficients for the different levels of CBV were also calculated to determine whether there was a difference between the validity of motion palpation at the different levels of the cervical spine. Palpation of the two patients with C2-3 CBV indicated substantial agreement $(\mathrm{K}=$ $0.756)$, whilst moderate agreement $(K=0.460)$ was indicated in the subject with the C5-6 block. In a normal cervical spine there is greater motion allowed at the C5-6 motion segment than at more superior segments, and one might therefore expect a total lack of motion at this C5-6 level to be easier to identify. However, this increased motion at C5-6 is particularly in the directions of flexion and extension, whereas the motion palpation evaluated in this study was in rotation and lateral flexion. Additionally, most people have more muscle and other overlying soft tissues in the mid and lower cervical spine through which to palpate, as compared to the more superficial C2-3 region. This may have contributed to the difference in results. It must also be pointed out that only 3 patients were included in this study, with only one having CBV at the C5-6 level. Therefore the discrepancy in these results may simply have been due to idiosyncrasies in the individual patients.

It was interesting to note that when palpating the subject with the C5-6 block, many examiners identified an upper cervical segment (C1-2 or C2-3) as the most hypomobile. It is possible that a true vertebral 'dysfunction' was present at the higher segment, causing a number of examiners to implicate it as their most hypomobility finding. The choice of this segment over the CBV caused the validity of motion palpation as assessed by this project design to decrease. Although it is unlikely that the kinesiopathology of a true vertebral dysfunction/fixation would affect greater hypomobility than a congenital fusion, it is possible that other manifestations of the 'joint dysfunction complex' were evident and detected by examiners. Despite simply being requested to identify fixation, other indica- tors of a joint dysfunction were being appreciated by the examiners. This suggests that when using motion palpation, examiners integrate the sense of kinesiopathology, with an appreciation of temperature change, muscle tension, tenderness, swelling, non-verbal pain response, as well as their instinctive ability to detect the site of the lesion.

\section{Limitations to the study}

In addition to the limitations stated above, the use of a congenital block vertebra in the validation of motion palpation has its limitations. The number of suitable subjects is restricted by the prevalence of the anomaly and the absence of complicating factors such as spinal degeneration, instability and pain.

Whereas previous motion palpation studies have used a pair of examiners and 40 patients/subjects, due to the scarcity of suitable patients with $\mathrm{CBV}$, the number of examiners had to be increased in order to have the same inferential power. This posed the problem of subject comfort, since even the most gentle application of motion palpation technique repeated over 20 times is likely to cause the subject discomfort. The use of so few patients also makes it difficult to separate any clinically relevant results from those attributable to the patient idiosyncrasies, and is likely to induce greater change in the minor fixation findings.

\section{Conclusions}

The results of this study indicate that even novice clinicians demonstrated the ability to correctly identify the presence or absence of known cervical spine intersegmental fixations by using specific motion palpation techniques on real patients with congenitally fused vertebrae. These congenital blocked vertebrae represent a true 'gold standard', allowing more accurate evaluation of the validity of motion palpation. The results of this study justify the clinical use of motion palpation in the diagnosis of true 'fixations' in the cervical spine.

\section{Competing interests}

None declared.

\section{Authors' contributions}

BKH and CP for formulation of research idea. BKH and $\mathrm{MD}$ for research design, and data collection. $\mathrm{BKH}$ and $\mathrm{CP}$ for manuscript preparation. All authors read and approved the final manuscript.

\section{Acknowledgements}

Anglo-European College of Chiropractic (AECC) for their assistance in the use of their equipment, facilities and administrative support. 
Carol Churchill, Administrative Assistant, Canadian Memorial Chiropractic College for typing the manuscript; and Bryan Groulx, Media Services, CMCC for the photographic work.

\section{References}

I. Riddle DL: Measurement of accessory motion: critical issues and related concepts. Phys Ther 1992, 72(12):865-874.

2. Strender LE, Lundin M, Nell K: Interexaminer reliability in physical examination of the neck. J Manipulative Physiol Ther 1997 20(8):516-520.

3. Nilsson N: Measuring passive cervical motion: a study of reliability. J Manipulative Physiol Ther 1995, 18(5):293-297.

4. Hagen KB, Harms-Ringdahl K, Enger NO, Hedenstad R, Morten H: Relationship between subjective neck disorders and cervical spine mobility and motion-related pain in male machine operators. Spine 1997, 22(I3): I50 I- I507.

5. Chen J, Solinger AB, Poncet JF, Lantz CA: Meta-analysis of normative cervical motion. Spine 1999, 24(I 5): $157 \mid$ - 1578

6. Jordan K: Assessment of published reliability studies for cervical spine range-of-motion measurement tools. J Manipulative Physiol Ther 2000, 23(3): $180-195$

7. Sandmark $\mathrm{H}$, Nisell R: Validity of five common manual neck pain provoking tests. Scand J Rehabil Med 1995, 27(3): |3|-136.

8. Van Suijlekom HA, De Vet HC, Van Den Berg SG, Weber WE: Interobserver reliability in physical examination of the cervical spine in patients with headache. Headache 2000, 40(7):58I-586.

9. Hubka MJ, Phlan SP: Interexaminer reliability of palpation for cervical spine tenderness. J Manipulative Physiol Ther 1994, I 7(9):59|-595.

10. Olson SL, O'Connor DP, Birmingham G, Broman P, Herrera L: Tender point sensitivity, range of motion, and perceived disability in subjects with neck pain. J Orthop Sports Phys Ther 2000, 30(I): $13-20$

II. Maher CG, Adams RD: Stiffness judgments are affected by visual occlusion. I Manipulative Physiol Ther 1996, 19(4):250-256.

12. Maher CG, Latimer J, Adams R: An investigation of the reliability and validity of posteroanterior spinal stiffness judgments made using a reference-based protocol. Phys Ther 1998 78(8):829-837.

13. Fjellner A, Bexander C, Faleij R, Strender LE: Interexaminer reliability in physical examination of the cervical spine. I Manipulative Physiol Ther 1999, 22(8):5II-5I6.

14. Smedmark V, Wallin M, Arvidsson I: Inter-examiner reliability in assessing passive intervertebral motion of the cervical spine. Man Ther 2000, 5(2):97-101.

15. Peterson DH, Bergmann TF: Joint assessment principles and procedures. In Chiropractic Technique Volume 3. Ist edition. Churchill Livingstone, New York; 1993.

16. DeBoer KF, Harmon R, Tuttle CD, Wallace $\mathrm{H}$ : Reliability study of detection of somatic dysfunction in the cervical spine. J Physiol Ther 1985, 8(I):9-16.

17. Mior SA, King RS, McGregor M, Bernard M: Intra- and interexaminer reliability of motion palpation in the cervical spine. JCCA 1985, 29(4):195-198.

18. Haas M, Groupp E, Panzer D, Partna L, Lumsden S, Aickin M: Efficacy of cervical endplay assessment as an indicator for spinal manipulation. Spine 2003, 28(I I): 1091-1096.

19. Seffinger M, Adams A, Najn W, Dickeron V, Mishra S, Reinsch S, et al:: Spinal palpatory diagnostic procedures utilized by practitioners of spinal manipulation: annotated bibliography of content validity and reliability studies. JCCA 2003, 47(2):93-109.

20. Haas M: Inter-examiner reliability of multiple diagnostic test regimens. J Manipulative Physiol Ther 1991, I4(I):95-I03.

21. Bergstrom E, Curtis $\mathrm{G}$ : An inter- and intra-examiner reliability study of motion palpation of the lumbar spine in lateral flexion in the seated position. European J of Chiropractic 1986, 34(3): $|2|-|4|$.

22. Love RM, Brodeur RR: Inter- and intra-examiner reliability of motion palpation for the thoracolumbar spine. J Manipulative Physiol Ther 1987, I O(I): I-4.

23. Boline PD, Keating JC, Brist J, Denver G: Inter-examiner reliability of palpatory evaluations of the lumbar spine. American J of Chiropractic Med 1988, I(I):5-II.
24. Keating JC: Inter-examiner reliability of motion palpation of the lumbar spine: A review of quantitative literature. American J of Chiropractic Med 1989, 2(3): 107-I I0.

25. Nansel DD, Peneff AL, Jansen RD, Cooperstein DC: Interexaminer concordance in detecting joint play asymmetries in the cervical spines of otherwise asymptomatic subjects. J Manipulative Physiol Ther 1989, 1 2(6):428-433.

26. Haas M: Statistical methodology for reliability studies. J Manipulative Physiol Ther 1991, I4(2): I 19-132.

27. Haas M: How to evaluate intraexaminer reliability using an interexaminer reliability study design. J Manipulative Physiol Ther 1995, I8(I): 10-15.

28. Breen $A$ : The reliability of palpation and other diagnostic methods. J Manipulative Physiol Ther 1992, I 5( I):54-56.

29. Hermann KM, Reese CS: Relationships among selected measures of impairment, functional limitation, and disability in patients with cervical spine disorders. Phys Ther 200I, $8|(3): 903-9| 4$.

30. Huijbregts PA: Spinal motion palpation: a review of reliability studies. I of Manual and Manip Ther 2002, I (1 ( ):24-39.

3I. Harvey D, Byfield D: Preliminary studies with a mechanical model for evaluation of spinal motion palpation. Clin Biomech 1991, 6(2):76-82.

32. Jull G, Bogduk N, Marsland A: The accuracy of manual diagnosis for cervical zygapophyseal joint pain syndromes. Med ] Aust 1988, |48:233-236

33. Seffinger M, Adams A, Najm W, Dickerson V, Mishra S, Reinsch S, Murphy L: Spinal palpatory diagnostic procedures utilized by practitioners of spinal manipulation: Annotated bibliography of content validity and reliability studies. J Can Chiro Assn 2003, 47:93-109.

34. Jensen $\mathrm{KJ}$, Gemmel $\mathrm{H}$, Thiel $\mathrm{H}$ : Motion palpation using a mechanical spinal model. European J of Chiropractic 1993, 41:67-73.

35. Barnsley L, Bogduk N: Medial branch blocks are specific for the diagnosis of cervical zygapophyseal joint pain. Reg Anesth 1993 , I 8(6):343-350.

36. Lord SM, Barnsley L, Bogduk N: The utility of comparative local anesthetic blocks versus placebo controlled blocks for the diagnosis of cervical zygapophyseal joint pain. Clin J Pain 1995 II (3):208-2I3.

37. Guebert GM, Yochum TR, Rowe LJ: Congenital anomalies and normal skeletal variants. In Essentials of Skeletal Radiology Volume 3. 2nd edition. Baltimore, Williams and Wilkins; 1996:210.

38. Andersson GBJ, Deyo RA: History and physical examination in patients with herniated lumbar discs. Spine 1996, 2I(24S): $10-18$

\section{Pre-publication history}

The pre-publication history for this paper can be accessed here:

\section{http://www.biomedcentral.com/1471-2474/5/19/prepub}

Publish with Bio Med Central and every scientist can read your work free of charge

"BioMed Central will be the most significant development for disseminating the results of biomedical research in our lifetime. "

Sir Paul Nurse, Cancer Research UK

Your research papers will be:

- available free of charge to the entire biomedical community

- peer reviewed and published immediately upon acceptance

- cited in PubMed and archived on PubMed Central

- yours - you keep the copyright

Submit your manuscript here:

http://www.biomedcentral.com/info/publishing_adv.asp
BiolMedcentral 